\title{
Long-term monitoring of a historic building to evaluate wall moisture content changes due to capillary-rise
}

\author{
Briggs, K.M. ${ }^{* a}$, Ball, R.J. ${ }^{\mathrm{a}}$, McCaig, I. ${ }^{\mathrm{b}}$ \\ a. Deparement of Architecture and Civil Engineering, University of Bath, Bath, UK \\ b. $\quad$ Historic England, Swindon, UK
}

\begin{abstract}
When impermeable ground bearing slabs are installed in buildings without a damp-proof course, it is believed that ground moisture will be 'driven' up adjacent walls by capillary action, however there is limited evidence to test this hypothesis. An experiment was used to determine if the installation of a vapour-sealed ground floor in a historic building would increase moisture content levels in an adjacent rubble-fill wall. This was achieved by undertaking long-term measurements of wall, soil and atmospheric moisture content over a three-year period. Measurements taken using timber dowels showed that the moisture content within the wall did not vary in response to wall evaporation rates and it did not increase following the installation of a vapourproof barrier above the floor. This indicates that the moisture levels in the rubble-fill wall were not driven by capillary rise.
\end{abstract}

Peer-review under the responsibility of the organizing committee of the ICMB21.

Keywords: Historic buildings; Conservation; Wall moisture levels

\section{Introduction/Background}

Water movement through masonry walls of historic buildings is an important process influencing wall deterioration (e.g. salt weathering) and damage to the internal environment (e.g. wall damp). It is believed that if an impermeable ground bearing slab is installed in an old building during renovation, ground moisture will be 'driven' up adjacent walls. Although there are references to this phenomenon, both in technical and product literature, there is limited evidence based on long-term monitoring.

A one-dimensional capillary rise model [1] indicates that water will rise within the pores of a wall via capillary action, if the wall has interconnected pore space and water is available at the base of the wall. The analytical model provided by Hall et al., [1] formed the basis for instrumentation and long term monitoring at a historic farm house in south Wales, UK; to measure wall moisture levels, to measure water at the wall base (soil moisture) and to measure the evaporative drying on the wall face.

\section{Aim \& objectives}

The aim was to determine if wall moisture levels were responsive to seasonal evaporation rates and if these were influenced by the installation of a vapour-sealed ground floor. The first objective was to determine whether seasonal changes in soil and atmospheric moisture content influenced the moisture levels within the rubble-fill wall. The second objective was to simulate the installation of an impermeable ground bearing slab by sealing the floor and measuring changes in wall moisture levels due to the intervention.

\section{Method}

Instrumentation was installed to monitor external weather conditions, internal atmosphere, wall moisture and soil moisture at the farm house. Instrumentation was installed in the pantry wall of the house (Figure 1a). The pantry was not heated. It had a flagstone floor and an approximately $600 \mathrm{~mm}$ thick, external rubble-fill wall forming the north elevation of the house. A TinyTag logger [2] was mounted on the internal face of the wall to measure internal temperature and relative humidity. A WS-GP1 weather station [3] was installed externally. The Schendel equation [4] was applied to calculate daily internal and external evaporation rates from these temperature $\left({ }^{\circ} \mathrm{C}\right)$ and relative humidity $(\%)$ measurements. A $1 \mathrm{~m}$ long access tube was installed externally to allow measurements of volumetric soil moisture content (\%) up to $1 \mathrm{mbgl}$ using a Pr2 Soil Moisture Probe [5]. The Soil Moisture Deficit (SMD) was calculated directly from the Soil Moisture Probe measurements taken at approximately monthly intervals. A continuous value of SMD was calculated directly from the weather station data using a water balance approach [6].

* Corresponding author. K.M.Briggs@bath.ac.uk

(C) The Author(s). This is an open access article distributed under the terms of the Creative Commons Attribution License (CC BY) 4.0 https:// creativecommons.org/licenses/by/4.0/, which permits unrestricted use, distribution and reproduction in any medium, provided the original author and source are credited. DOI: 10.14293/ICMB210012 


\section{ICMB21}

Seven, $130 \mathrm{~mm}$ long, $12 \mathrm{~mm}$ diameter holes were drilled into the internal face of the pantry wall at $0.2 \mathrm{~m}$ spacing between $0.2 \mathrm{~m}$ and $1.4 \mathrm{~m}$ above ground level. Pine dowels (10 $\mathrm{mm}$ diameter) were installed in the wall and sealed with plumber's putty. Calibration of the timber dowels [7] showed that they took approximately 14 days to equilibrate and provided a good indicator of relative changes in wall moisture, however absolute values at dowel moisture contents $>15 \%$ may be underestimated. The timber dowels were weighed at approximately monthly intervals between January 2017 and March 2020. A vapour-proof barrier was installed along the length of the pantry wall on $18^{\text {th }}$ September 2019.

\section{Results}

The internal and external temperature $\left({ }^{\circ} \mathrm{C}\right)$ and relative humidity $(\%)$ data showed evaporative drying during the summer months, followed by reduced drying through the winter months. The Soil Moisture Deficit (SMD) data showed that soil water was available at the base of the wall during the winter and spring months of the monitoring period, as shown by a zero value. If applied as boundary conditions to a capillary rise model [1], the atmospheric and soil moisture measurements would indicate higher moisture content in the wall during the spring and winter months (reduced drying), relative to the drier summer months.

Figure $1 \mathrm{~b}$ shows the dowel moisture (mass) content values taken at approximately monthly intervals between March 2017 and March 2020. The measurements show that the dowel moisture content was close to $50 \%$ moisture content at the base of the wall and consistently greater than higher up the wall. The data show that the moisture level of the dowels, and by implication the wall, did not vary in response to seasonal evaporation rates. Nor did the dowel moisture levels immediately increase in response to the sealing of the flagstone floor. Inspection showed that moisture levels rapidly increased beneath the vapour-proof barrier within two days of installation, indicating ground moisture transfer through the floor and into the internal environment of the room.

\section{Conclusions}

The following conclusions can be drawn from the results presented:

1) The rubble-fill wall had the greatest moisture levels close to ground level, with reduced moisture levels at greater height (up to $1.4 \mathrm{~m}$ ). The moisture levels in the wall did not vary in response to seasonal changes in wall evaporation rate and the supply of water at the wall base, indicating that the wall was unaffected by capillary rise. It is possible that the composite nature of a rubble-fill wall is not conducive to water uptake through capillary action beyond the $0.2 \mathrm{~m}$ zone at the base.

2) The wall dowel moisture contents did not immediately increase following the installation of a vapour-proof barrier. However, continued monitoring is required to establish whether wall moisture content increases in the longer-term.

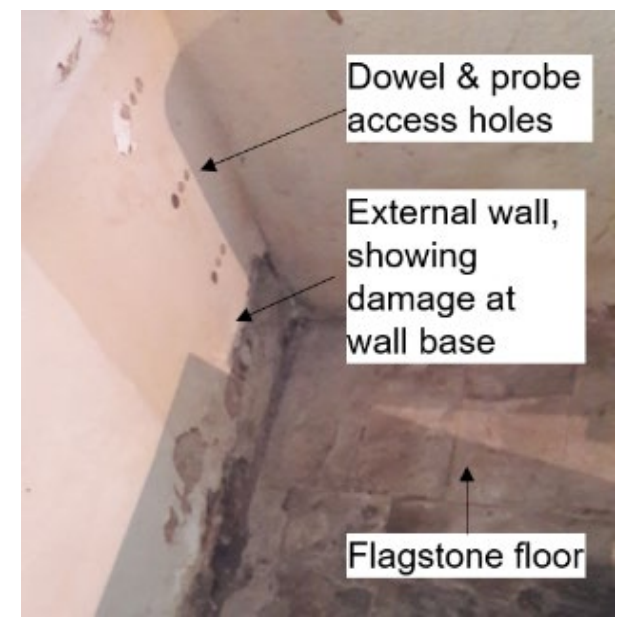

(a)

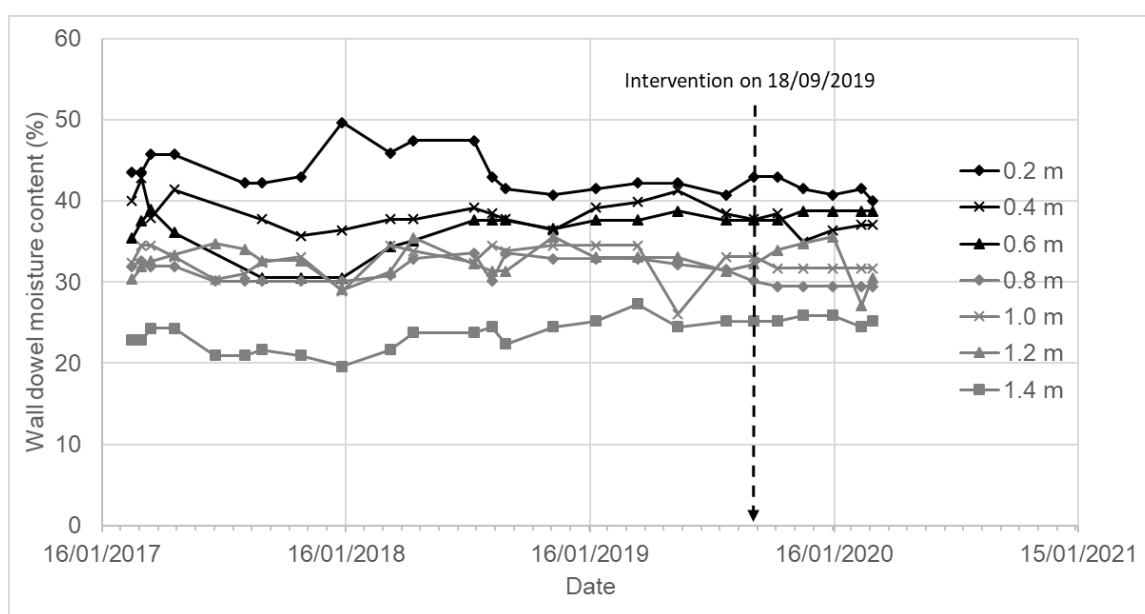

(b)

Figure 1. (a) The external pantry wall of the farm house in south Wales, UK, showing the location of wall dowel and moisture probe access holes; (b) Measurements of wall dowel moisture content (by mass) between $0.2 \mathrm{~m}$ and $1.4 \mathrm{~m}$ above ground level over a three-year period between 2017 and 2020 , including an intervention to seal the floor on 18/09/2019.

\section{References}

[1] Hall, C., et al., (2011). Moisture dynamics in walls: response to micro-environment and climate change. Proc. of the Royal Soc. A, 467(2125), pp.194-211.

[2] TinyTag (2019). TinyTag Plus 2 Datasheet, TGP-1417. Issue 11, 2019

[3] Delta T Devices, (2020). WS-GP1 Weather Station Datasheet, version 4.

[4] Schendel, U., (1967). Vegetationswasserverbrauch und-wasserbedarf. Habilitation, Kiel, 137, pp.1-11.

[5] Delta_T Devices, (2020). PR2 Profile Probe SDI-12 Data Sheet

[6] Smethurst, J.A., Clarke, D. \& Powrie, W., (2006). Seasonal changes in pore water pressure in a grass-covered cut slope in London Clay. Géotechnique, 56(8).

[7] Walker, R., et al., (2016). Measurement of moisture content in solid brick walls using timber dowel. Materials and structures, 49(7), pp.2549-2561. 